\title{
The Effect of Group Hope Therapy Integrated with Mobile Learning on Hope and Perceived Stress Levels in MS Patients
}

\author{
Navid Kalani' ${ }^{1}$, Leili Mosalanejad ${ }^{2}$, Hassan Zabetian ${ }^{3}$ and Saeed Abdolahifard ${ }^{4}$ \\ ${ }^{1}$ Medical ethic Research Center, Jahrom University of Medical Sciences, Jahrom- Iran \\ ${ }^{2}$ Assistant Professor, Educational Development Center, Research Center for Social \\ Determinants of Health, Jahrom Universty of Medical Sciences, Iran \\ ${ }^{3}$ Department of Anesthesiology, Research Center for social Determinants of Health, \\ Jahrom University of Medical Sciences, Jahrom- Iran. \\ ${ }^{4}$ Student Research Committee, Shiraz University of Medical Sciences, Shiraz, Iran.
}

DOI: http://dx.doi.org/10.13005/bbra/1861

(Received: 14 July 2015; accepted: 15 September 2015)

\begin{abstract}
MS is a chronic, progressive disease of the central nervous system which is characterized by chronic inflammation and destruction of the nervous system neurons. Following this illness, physical disabilities and mental changes occur on which are effective on the MS patient's self-esteem and his quality of life. This study is an experimental study before and after intervention. In this study, all patients with chronic physical and mental illness other than MS, more than years had passed since their diagnosis, were literate, and with a non progressive form of MS were included in the group. The group sessions were held to all patients with including criteria and at that meeting the patients completed the Perceived Stress Scale and Hope Schneider Questionnaire. Then people in 10 sessions participated in a group hope therapy. Then they received the complementary intervention through a mobile phone with meaningbased messages that contained sentences on hope and promoting inhibition of stress. Samples. In the end, the post-test was performed on patients and the means were compared with each other. The results showed that the mean expectancy increased after the intervention $(p=0.02)$. Moreover, the perceived stress levels decreased after the intervention. $(P=0$. 0001). Using methods such as hope therapy with mobile based learning have a special place in this context and they increase hope and reduce stress levels in patients with multiple sclerosis. So, with effectively planning and the usual treatments, we can improve mental health and even improve the prognosis of these patients.
\end{abstract}

Key words: Multiple sclerosis, hope, perceived stress, hope therapy.

MS is a chronic, progressive disease of the central nervous system which is characterized by chronic inflammation and destruction of the nervous system neurons ${ }^{1}$. This illness involves the active layer of the society and is the second factor in the inability of young people ${ }^{2}$. And it is usually diagnosed in patients between 20 and 40 years. More women than men, in a ratio of 2 to 1 ,

\footnotetext{
* To whom all correspondence should be addressed. E-mail: saedparsa2012@gmail.com
}

are diagnosed with $\mathrm{MS}^{3}$. According to the National MS Society in Iran; about 7,000 people are the members of this forum. MS prevalence in Iran is about 15 to 30 cases per 100 thousand people ${ }^{4}$. Clinical signs and symptoms include optic neuritis, diplopia, ataxia, dizziness, weakness, limb movement disorders, genitourinary disorders such as: Neurological bladder, urinary incontinence, impotence, constipation, sleep disorders and depression. These effects, because of its debilitating effects, encompass all aspects of the life of the patient and as a result disrupt the normal 
course of a patient's life. Today, despite the impressive advances in medical knowledge, the main cause and how to cure this disease has still remained unknown. And nobody knows what fate awaits these patients ${ }^{5}$. Since these patients have to confront both the stress of everyday life, and stresses derived from symptoms of the illness which are fluctuating and unpredictable, so the progress of the disease may interfere with the patient's work, family life, social relationships and activities $^{6 .}$ This disease threatens the individual's ability and independence to participate effectively in society and family and leads the patients to lack of self competence and self assurance and have an impact on his image of himself. Implications for Multiple Sclerosis protest strongly affect the perception of one's self and have very detrimental effects on self-esteem ${ }^{7}$. It has been estimated stress is the cause of 50 to 80 percent of disease. One of the illnesses that stress triggers and compounds Cholera is a disease that stress as a trigger, it is less likely to cause disease, is multiple sclerosis $(\mathrm{MS})^{8}$. In 85 to $90 \%$ of MS patients there are exacerbation and recovery terms which are unpredictable. Since then it has been shown that psychological stress leads to activation of this disease ${ }^{9}$. In a longitudinal study by Ackerman et al (2002) performed on 23 patients with MS for one year, it was revealed that $85 \%$ of exacerbations of MS had returned after stressful events. And in fact, stress is an active agent in reverting MS in patients ${ }^{10}$.The idea that psychological stress can exacerbate MS patients should be based on more than a hundred years ago in which Charcot (1877) thought that sadness, irritation and adverse changes in social events can be related to the onset of the disease ${ }^{9,10}$. Failure in diagnosis of the disease, unpredictability of the disease, concerns about medical costs, inability to self care, lack of amenities in the home and workplace and increase in the cost treatment are among the stressfuldriving situations that derive from Multiple sclerosis disease ${ }^{11}$. The reports of studied by Ackerman et al (2002), Gab et al (2003), Karvnakaran (2004), Long Vshvltz Mayer (2000), Mohr et al (2004) show that several factors, including psychological factors such as preoccupations associated with this diseases, fear of dying and concerns about the future and social factors such as job loss and supplying the costs of treatment are among the main stresses in MS patients. (10 V13-12) Moreover, the recent report of Neurology Society of America showed that one of the main factors MS patients is the stress of life events. Researchers at this University studied on 73 patients from 18 to 55 years for more than a year. The study results showed that there was a significant relationship between the patient's reports on stressful life events and the exacerbation of his illness ${ }^{10}$. The results of a study under the name of investigating the relationship between stress and relapse rate in patients with MS (2006) has shown that the symptoms of frequent relapses and hospitalizations in patients who have higher levels of stress were higher. The results of this research showed that $85 \%$ of exacerbations of MS had relations with stressful events in the patient's life. In this study, stressful events occur in an average of 14 days before symptoms ${ }^{(14) .}$ MS disease also alters the pattern of family communication. On the other hand, families should also think about the problems caused by the treatment. Family activities usually changes with multiple sclerosis disease. Due to the progressive nature of the disease, many patients lose their jobs and this leads to a decline in life revenues that itself is stressful ${ }^{16-15}$. Today, several ways have been developed to combat and inhibit stress but one of the most promising approach is a cognitive - behavioral approach including identifying sources of stress, the reaction to stress and finding ways to reduce stress. This approach, especially when chronic pain or chronic stressors is useful ${ }^{17}$. The cognitive - behavioral therapy is a combination of two approaches to understanding health behavior. Indeed, in this approach, behavior therapy and cognitive therapy approach to the strengths of objective assessment on the one hand, the role of memory interference in rebuilding their past record and interpret information gathered on the other ${ }^{18}$. In a study, Gross et al (1999) tested the effects of cognitive-behavioral training interventions on improving stress in HIV-infected patients. Their interventions included relaxation training, psychological effects of stress, cognitive - behavioral therapy, stress and emotions, understanding cognitive disorders, negative automatic thoughts, replacing rational thoughts instead of their social skills that were taught over 10 weekly sessions. The results of their studies 
showed that the stress in patients undergoing cognitive-behavioral training interventions significantly reduced ${ }^{19}$. Moreover, based on the studies, the relationship between stress and MS exacerbations may not be fully understood, but it seems to be important in reducing stress and inhibition of this disease. Positive psychology and health psychology emphasize increase happiness and health and scientific research on the role of personal strength and positive social systems in promoting optimal health. The main themes of positive psychology oriented include happiness, hope, creativity and wisdom ${ }^{20}$. A branch of health psychology is nervous safety psychological that deals with the impact of psychological factors on the immune system and increase the disease risk. Major findings in this area is that personality, behavior, emotion and cognition can all alter immune response and therefore modify the disease risk. This field of study hopes that psychotherapy can be useful for the prevention and treatment of physical illness ${ }^{21}$. Hope therapy is derived from cognitive-behavioral therapy, problem focused strategies and treatment fictional narrative bridge ${ }^{22 .}$ Hope is like a placebo and has biological effects and can cause activation of brain circuits and the release of endorphins and enkephalins in the body and positively affect the management of pain and physical disability in patients ${ }^{23-24}$. The first attempts to define and measure of hope, dates back to the work of Schneider et al in the past two decades. Schneider et al., recognize hope as something composed of elements of will power or thinking, or thinking of advance planning, the aim of identifying obstacles $^{25}$. Schneider in psychological treatments has considered hope as the main goal of treatment. $\mathrm{He}$, as the founder of the theory based on health expectancy, defined hope as structural design which includes the ability to pass on the desired goals despite the present obstacles and creating an incentive to use these paths ${ }^{26}$. In his view, frustration causes physical and psychological illnesses. Schneider's research on mental illness and some physical ailments such as cancer, suggests that many diseases can occur or be exacerbated in response to the loss of hope and hope therapycan improve mental health and the quality of life of patients ${ }^{27}$. Irving et al (1998) also showed that hope training can have different psychological benefits for the patients and also increase the components the joy in them ${ }^{28}$. In another study, Schneider and Lopes (2002) have regarded hope as a placebo in the treatment of physical and mental illness, and stated that hope creates positive changes in human physiology ${ }^{26}$. Bijar (1388) in a study to evaluate the effectiveness of group therapy based on promising approach to increasing the life expectancy of patients with cancer, achieved the results in the treatment group compared with the control group-based approach to health expectancy significantly increase life expectancy and reduce depression ${ }^{(29)}$. The results of studies by Group (2005) and Schneider and Framework (2005) on patients with malignant disease, showed that belief and expectation could have potential effects on the central nervous system. That's why those hoping to improve the beliefs and expectations of a healthy positive outcome more quickly improved ${ }^{30-31}$. In addition, those whose hopes are high, have greater ability to solve social problems are going to be those who are willing bottom ${ }^{32}$. According to Schneider, hope is a perception concerning the future, so if MS patients have hope for the future, they may be in a better position to feel about their different quality of life. And to accomplish this, a good life, in turn, will increase the feeling of hope in these patients ${ }^{22}$.

Quality of life of MS patients require fundamental changes in their views about the current and future status of the disease and its impact on their lives and techniques, such as drug therapy is not able to provide these changes, so the use of methods such as hope therapywith a message of in this regard has a special place. Despite the importance of these therapies, no attention has been attached to it in establishing motivation and creating behavior in areas related to health and the scarcity of research in this area is evident. According to various studies, patients hoping for a healthy recovery due to positive beliefs and expectations, can recover more quickly and have more successful treatment. Quality of life of MS patients require fundamental changes in their views about the current and future status of the disease and its impact on their lives and techniques, such as drug therapy is not able to provide these changes, thus the use of methods such as psychological intervention has a special place. Despite the importance of these therapies, 
no attention has been attached to it in establishing motivation and creating behavior in areas related to health and the scarcity of research in this area is evident. Therefore, the present study was performed with the aim of evaluating the effect of hope therapy with mobile based learning on expectancy o and perceived stress in MS patients.

\section{MATERIALSAND METHODS}

This paper is an experimental study was performed before and after intervention. The study population included all patients who were members of the MS Society in Jahrom who are estimated to reach 100 , of these patients, those who had not chronic physical or mental illness, were not in the progressive and disability phase of the disease, only after the elapse of more than a year since the diagnosis of their illness, did they feel and accept the disease problems and be involved with it and were selected. These people enrolled out of their personal will and whenever they wished they could be excluded. Then a group meeting was convened with all the studied participants and the process of doing research and conditions of participation in group meetings were discussed. At the first meeting, the patients filled in two questionnaires of Perceived Stress Test and Schneider Hope questionnaire. After the completion of the intervention the questionnaire was completed again. Continuation of the sessions and the main intervention were through mobile based learning . Data collecting tools in the present study were the two questionnaires of Perceived Stress Test and Schneider Hope questionnaire . Perceived stress in these patients was evaluated with Perceived Stress Scale, which was built in 1983 by Cohen et al . This scale has 14 items and each item is answered on a five-point Likert scale (none, low, medium, high and very high); these options are scored 0, 1, 2, 3 and 4, respectively and are the two subscales positive and negative perceptions of stress niche. 1) Subscale negative perception of stress and, 2) subscales positive perception of stress that each of these two subscales is with 7 items. Through writing the questions of this questionnaire, respondents express their ideas on the uncontrollability, unpredictability and hardship of their lives. This scale also has some direct questions about the current levels of stress on the individual. The internal consistency reliability coefficients scale has been attained through Cronbach's alpha in a range of 0.84 to 0.86 in the two groups of students and a group of smokers in cessation program. This is a good tool for measuring the overall experience stress in different age groups. (Cohen et al. 1995) ${ }^{33}$.

Mymvra and Griffith (2004) is a research on Japanese students obtained Cranach's alpha coefficient of the original and revised scale Japanese as 0.88 and 81 , respectively, that these reliability coefficients are close to those of the original ${ }^{34}$.

\section{Schneider Hope Scale adults}

A self-report scale that was developed for individuals 15 years of age and has 12 questions and two subscales of the components and the bus is operating. The questions are in a multiple choice fashion and are in a continuum of $4^{\circ}(1=$ totally wrong and totally true $=4$ ). So, the scores range will be between 8 and 32. 4 questions are about the bus in operation, 4 questions are diversion and other questions are not scored. Total scores of subscale of the bus will constitute the overall score of hope. Preliminary evidence for the validity and reliability of this test is provided by Snyder et al. Cronbach's alpha has been obtained between 0.74 and 0.84 and its test - retest reliability in a 10 -week period has been $0.8^{22}$.

Patients, who completed the questionnaire, participated in 10 sessions as a hope therapy and received positive messages containing the words mean through their mobile phones that strengthened a sense of motivation and hope in these patients and helped manage the stress in them. Study samples received two messages suit the context of standard hope therapy each week in 4 days.

\section{Topic of the sessions}

a) First session: implementation of the questionnaire and explain the procedure

b) Second Session: MS and its diagnosis, prognosis and treatments:2 session

c) Finding hope: Definition of hope and its positive consequences: 2 sessions

d) Consolidation of hope: the hope of organizing components:2 sessions

e) Promoting hope, creating specific goals in life. 1 sessions

f) Hope maintenance: practice to achieve life 
goals:2 sessions

g) The last session: Implementation of posttest and filling both questionnaires again: 1 session are as follows:

Text messages that were sent to patients

\section{Some messages are as follows}

I am happy with my health, so I will let others know what has helped me.

Share experience and sense of hope and patience with people who suffer from MS and tell them that you can overcome any disease with hope, confidence and self-esteem.

When one door of happiness is closed on us, another opens; But we often look so closed the closed doors open that we are unable to see the open ones, If you did not reach the goal (to overcome the disease with effort, patience, perseverance and patience) we should not consider that we have been unsuccessful, but another door is open to us and that door id nothing but hope.

The first step in dealing with your MS is to keep your spirit, cope with the disease with confidence and hope toward the future and live your normal social life and spend more useful than ever before.

Never compare your own treatment approach with that of other patients since drug treatment is taken as appropriate depending on your specific symptoms and conditions.

Faith does not mean that your ship will never experience a hurricane, but that your ship will never be drowned. The steps your treatment process may take time but patience, and patience of hope in our Lord, the God will give you a taste of patience and wait for us.

To analyze the data, they were entered in spss software version 16 and analyzed using descriptive statistics and then analytical statistic as paired t- test.

\section{RESULTS}

Of the participants, $64.3 \%$ were female and $35.7 \%$ were allocated to men. $3 \%$ of the participants were single and others were married. $43 \%$ of people had university education, $46 \%$ had a high school education and the education cycle and were lower. Most people were in the age range 36-45 years, $59.4 \%$, 34\% aged 25-35 years, and the rest were older than 45 years.

The results of (Table 1) show that the motivation of expectancy indicators increased in the post-intervention. And the average scores of hope have improved. Mean score of pathway subscale was significant.

The results in Table 3 show that although the level of expectation before the intervention does not have any differences between the two genders, the mean of expectancy in two groups were significant $(\mathrm{P}=0.04)$ and its rate has improved in men higher than in women. Although the overall stress levels also decreased in both groups, the difference was not significant between the two groups.

Table 1. Mean hope and indices in patients before and after intervention

\begin{tabular}{|c|c|c|c|c|c|c|}
\hline \multirow{2}{*}{$\begin{array}{l}\text { Expectancy } \\
\text { Subscale }\end{array}$} & \multicolumn{2}{|c|}{ Before intervention } & \multicolumn{2}{|c|}{ After intervention } & \multirow[t]{2}{*}{$\mathrm{T}$} & \multirow[t]{2}{*}{ Significance } \\
\hline & $\begin{array}{l}\text { mean } \\
\text { SD }\end{array}$ & & $\begin{array}{l}\text { mean } \\
\text { SD }\end{array}$ & & & \\
\hline Agency & 13 & 1.97 & 13 & 1.57 & 0.52 & 0.6 \\
\hline Pathway & 11 & 1.97 & 13 & 2,24 & & 0.02 \\
\hline Total hope & 25.16 & 3.8 & 26.04 & 3.19 & & 0.25 \\
\hline
\end{tabular}

The results in Table 2 also show a decrease in perceived stress levels in patients with( $\mathrm{p}=0001)$

Table 2. Mean perceived stress in patients before and after intervention

\begin{tabular}{lcccc}
\hline $\begin{array}{l}\text { Perceived stress Test } \\
\text { Total stress test }\end{array}$ & $\begin{array}{c}\text { Before intervention } \\
\text { SD Mean }\end{array}$ & $\begin{array}{c}\text { After intervention } \\
\text { SD mean }\end{array}$ & T & P \\
\hline & $39.25(6.84)$ & $26.91(7.01)$ & 6.39 & 0.001 \\
\hline
\end{tabular}


In the end, the qualitative analysis of the patients' analysis was evaluated. Patients believed that this type of training has created new hope for them, and as a result had made suffering from the disease easier for them, and also were satisfied with the attention given by the medical staff in training them and expressing their problems and many of them stated that they do not delete the messages frequent review of their mobile text messages to delete from the cell phones for frequent review. Moreover, many of them, such as the impact on reducing stress, anxiety, social isolation, improve communication, a sense of hope and healing, feeling defeated and better living conditions for them has the disease.

Table 3. The difference and mean of the variables in the two sexes

\begin{tabular}{|c|c|c|c|c|c|}
\hline Variables & & Groups & Mean (SD) & $\mathrm{T}$ & $\mathrm{P}$ \\
\hline Hope & Pathway & women & $13.05(2.07)$ & $0 . .31$ & 0.76 \\
\hline \multirow[t]{4}{*}{ Before the intervention } & & men & $12.66(1.52)$ & & \\
\hline & Agency & women & 11.85(1.98) & 0.92 & 0.96 \\
\hline & & men & $11.75(2.21)$ & & \\
\hline & Pathway & women & $12.40(1.14)$ & 0.04 & 0.85 \\
\hline Hope & & men & $11.75(2.21)$ & & \\
\hline \multirow[t]{2}{*}{ after the intervention } & Agency & women & 13.23(2.42) & 0.46 & 0.08 \\
\hline & & men & 11.85(1.98) & & \\
\hline \multirow[t]{2}{*}{ Total expectancy } & & women & $25.78(3.27)$ & 0.03 & 0.04 \\
\hline & & men & $27.66(0.57)$ & & \\
\hline \multirow[t]{4}{*}{ Stress } & Before & Women & $39.90(6.41)$ & 0.22 & 0.71 \\
\hline & & Men & 34.66(8.08) & & \\
\hline & After & Women & 27.11(7.34) & 0.8 & 0.68 \\
\hline & & Men & $26.20(6.34)$ & & \\
\hline
\end{tabular}

\section{DISCUSSION}

In the present study, hope indices have increased in the post-intervention phase, while no significant difference in the pre-intervention phase was seen, that these results are consistent with the results of the present studies.

In their study by Taghadosi et al (1388) under the name of a review of the effectiveness of interventions promoting hope in patients with cancer, it was showed that a significant difference was seen between the mean of the scores of hope in the patients of study and control groups before the promoting hope interventions in study and control groups. The average score of hope in the experimental group increases 4.32 after the intervention and there was a significant difference between the mean scores before and after the intervention group. There was no significant difference in between the mean of the scores of hope in the patients of study and control groups before the promoting hope interventions. After completion of interventions promoting hope, there was a significant difference between the mean of the scores of hope in the study and control groups Haras (2000) in a study entitled rising hope in the early stages of cancer recurrence, performed interventions to increase hope in these patients that there were significant differences in expectancy level between the intervention group and the control group and in the quality of life in both intervention and control groups ${ }^{36}$. In the study of Rafsanjani et al under the name of the effect of treatment on the promotion of moral and spiritual health of patients with colorectal cancer in Kerman, it was shown that there was a significant difference in comparing the mean hope score between before and after intervention ${ }^{37}$. The study by Bijari et al examined the effectiveness of group therapy as a promising therapeutic approach based on the increase in life expectancy of women with breast cancer; it was shown that group therapy based on a promising therapeutic approach in comparison with the control group significantly increased the life expectancy in women with breast cancer ${ }^{29}$.

Cheavens (2006) in their study showed that promising therapeutic agent can increase thinking (thinking hopefully one of the 
components), the meaning of life and self-esteem and decrease depressive symptoms. In a study by Sotudeh Asl, et al under the name of a comparison of two methods of medication and therapy on quality of life expectancy of patients with essential hypertension, it was shown that hope therapy improved the quality of life in patients with essential hypertension more than drug therapy and the effects of treatment after three months of the end of the intervention was still in place. The results of these studies indicate the effects of hope promoting interventions for patients and support the place of hope in palliative care as an important element of protection. The results of the present study seem to be compatible with the findings of the above mentioned ones ${ }^{39}$.

In this study, the level of the perceived stress in patients decreased, which is consistent with the results of the following studies.

The results of the study by Pedram et al with the subject of the effectiveness of cognitivebehavioral therapy in the treatment of anxiety disorders, depression, and create hope for women with breast cancer in Ahvaz showed that cognitivebehavioral group therapy sessions have a positive impact on reducing anxiety and on increasing their hope $^{40}$.

In an intervention based on concentration and reducing stress during the 8 weeks on 19 women with breast cancer, it was found that these interventions have positive effects on mood and quality of life in breast cancer patients in the form of improved mental stress, physical symptoms and psychosocial characteristics ${ }^{41}$.

In an experimental study on relaxation exercises for 8 weeks, 30 patients suffering from heart diseases, the results showed that relaxation has a positive effect on reducing stress and physical characteristics of Chinese patients with heart failure ${ }^{42}$.

In a study on the effectiveness of problembased therapy on 50 patients with cancer, the results showed that the quality of life and reducing stress are significant ${ }^{43}$.

The results of this study show that although there is no difference in the level of expectation in both sex before the intervention, however after the intervention the mean level of expectancy with $\mathrm{p}=0.04$ in the two groups were significant, and its rate improved higher in men than in women. There is no difference in the level of stress in both sexes before the intervention and after the intervention with, in spite of reducing stress levels in the two groups, was not significant which is again consistent with the results of the present study.

In a study by Fallahzadeh et al. under the name of comparing the life expectancy of men and women in Yazd province, it was shown that life expectancy in men was higher than in women ${ }^{44}$.

In this study, it is important that a method has many advantages leading to facilitate and speed up the healing process. Among them, many patients with MS are afflicted with a sense of the uniqueness of the problems and thoughts. This sense of uniqueness by these patients will exacerbate their social exclusion and boost a unique feeling of being socially isolated in them. In general, it can be concluded that interventions of promoting hope are effective in increasing the level of hope in patients, so in order to improve the quality of life in patients with MS, it is appropriate to provide educational services and programs with the hope of promoting good practices such as problem-based learning with active participation of the patient in the process of discussing with modern planning.

In the end, it is suggested that the research through the use of diagnostic tools expectancy factor in patients with MS and comparing the results with the results of the present study be performed. And also regarding the fact that families are the primary caregivers for patients, in the research which are conducted with the aim of preserving and promoting hope and ultimately improve the health of patients, a number of interventions should be designed and provided for the patients' families. Training all health care staff to help patients cope with their problems and instill hope to patients seems to be highly necessary.

\section{CONCLUSION}

The use of methods such as health expectancy using complementary methods such as mobile-based learning have a significant role in the education of the public and in health promotion role and can increase hope and reduce the perceived stress in patients with multiple sclerosis, so we 
can help improve mental health of these patients and even help improve their prognosis through effective planning along the usual treatments.

\section{ACKNOWLEDGEMENTS}

I appreciate all participant from ms association in this research.

\section{REFERENCES}

1. Heidari Sureshjani S, Eslami AA, HassanzadehA. The Quality of Life among Multiple Sclerosis Patients in Isfahan.Health system Reserch journal; 2012; 5(7):571-79.

2. Taghi Z, quality of life in ms patients related to ms association. Mazandaran. Iran Nursing Journal. 2009

3. National ms society, (2008). what causes, retrieved January, 2009, from :www.nationalms society.org

4. Bakhshaie N M , Khosravi m, Rafie M. The cognitive performance in multiple sclerosis patients Ms. congress of psychologist community in Iran. 2012.

5. Braun, WE. Harrison's principles of internal medicine.16th edition.Newyork: MCGrawhill; 2005, P

6. Malcomson KS,Dunwoody L,low-strong AS,psychological intervention in people with multiple scelerosis.J neurd.2007:254:1-13.

7. Linda Morgante., Hope in Multiple Sclerosis: A Nursing Perspective. International Journal of MS Care: 2000; 2(2): 9-15. doi: http://dx.doi.org/ 10.7224/1537-2073-2.2.9.

8. Phips l, kasmier V. stress and control. Translated by Namavar H, Chehr publication, Tehran.1995

9. Bulijevac D,hope,W.C.J.,reedker W., Janssens, A.C.J. W., Vandermeche, F.G.A., Vandoorn, P.A and Hintzen,R.Q, Self reported stressfull life events and exacerbations in multiple sclerosis:prespective study.British Medical Journal, 2003; 327: 646.

10. Mohr DC,Hart S.L,Julian L.and Pelltier D., Assosiation between stressful life events and exacerbations in multiple sclerosis:ametaanalysis.British Medical Journal, 2004; 328: 731.

11. Black JM,Hawaks JH.medical surgic nursing. philadelphia:W.B.saunderscom; 2005.

12. Mohr DC1, Pelletier D. A temporal framework for understanding the effects of stressful life events on inflammation in patients with multiple sclerosis. Brain Behav Immun. 2006; 20(1):2736.
13. Langenmayer A,Scholttes N.psychotheraph with multiple sclerosis patients. psychological representation 2000; 2: 495-508.

14. Acreman KD,Heyman R,Rabin bs,Anderson 14-Houck PR,Frank E,etal.stressful life events precede exacerbation of multiple sclerosis. psycosomatic medicine.2006; 64: 916-920.

15. Kobelt G,Berg J,Lindqren P,Gerfin A,Lutz J.cost and quality of life of ms.Eur Journal Health Econome. 2006; 2(7):586-595.

16. Phillips CJ.the cost of multiple sclerosis and the cost effectiveness of disease-modifying agents in its treatment. CNS Drugs. 2004; 18(3): 561-574.

17. Simon H,Cannistra SA,Etkin MJ,Codine JE,Huang D,Heller D,Shellito DC,and Stren TA., stress.nidus information services, inc, 2001.

18. Beck Js.Cognitive behavioral therapy.Guilford press. 2011

19. Antoni MH,Gruess S,Gruess DJ,Kumar M,Lutgendrof S,Ironson G,Dettmer E,Williams I,Kilmas N,,Fletcher MA,and Schneiderman $\mathrm{N}$, Cognitive-behavioral stress management reduces distress and hour urinary free cortisol out put among symptomatic HIV-infected gay man annls of behavioral medicine, 1999; 22: 2931.

20. Compton, William C. Introduction to Positive Psychology.Belmont, CA, US: Thomson Wadsworth. 2005.

21. Raisian AS. The effectiveness of hope therapy on decreasing depression and prevention of recurrence in treatment of substances abuse. Research in Addiction and Substance Abuse 2011; 5(17).

22. Snyder CR, handbook of hope:theory,measures and application. academic press.usa, 2000.

23. Snyder CR, Rand KL. Hopelessness and health. In N. Anderson (Ed.) Encyclopedia of health and behavior. Thousand Oaks, CA: Sage. 2005; 521-523.

24. Seligman MEP, Csikszentmihalyi M . Positive psychology: An introduction. American Psychologist. 2000; 221-278.

25. Snyder CR,Anderson J.Hope and health: measuring the will and ways, handbook of social and clinical psychology:the health prespective.new York:program press, 1991; 285305.

26. Snyder CR, Lopez S. Striking abalance. Acomplementary focus on human weakness and strength American psychological association. 2003

27. Snyder CR, Irving L, Anderson JR. Hope and Health: Measuring the Will and Ways, In: C. R. Snyder D. R. Forsyth(Eds.), Handbook of Social 
and Clinical Psychology: The Health Perspective. New York: pergamon Press; 1991: 285-305.

28. Irving ML,Snyder CR, and Crowson JJ., hope and coping with cancer by college females. Journal of Personality, 1998; 66: 195-214.

29. Bijari H, Ghanbari Hashemabadi B, Aghamohammadian H,Homaie F. the survey of effcectiveness of group therapy based on hope therapy in increasing life expectancy in women with breast cancer. Journal of Education and Psychology. 2010; 10(1): 172-185.

30. Groopman J.the anatomy of hope:how people prevail in the face illness.American psychological 2005; 14(2): 79-91.

31. Snyder CR,Rand KL.Hopelessness and health.IN N.Anderson (ED). encyclopedia of health and behavior 2005.

32. Bahari F, Fatehizadeh M, Ahmadi SA,Molavi $\mathrm{H}$, Bahrami F . The effect of hope, forgiveness and combined marital counseling on interpersonal cognitive distortions of divorcing couples.ReSearch in Behavioral Sciences 2009; 8(1): 25-33.

33. Cohen S, Kamarck T, \& Mermelstein R. A global measure of perceived stress. Journal of Health and Social Behavior 1983; 24: 385-396.

34. Mimura C, \& Griffiths P. A Japanese version of the perceived stress scale: translation and preliminary test. International Journal of Nursing Studies 2004; 41(4): 379-385.

35. Taghdisi MH, ABDI $n$, Naghdi S. The effectiveness of hope increasing approach in patients with cancer in Sanandaj. Armaghandanesh 2009;14(3): 24-34.

36. Herth K. Enhancing hope in people with a first recurrence of cancer: J Adv Nurse 2000; 32(6):1431-41.

37. Rafsanjani H, Sadat T. The effect of group spiritual therapy on increasing mental health and spiritual health in patients with colorectal cancer in Kerman. Msc dissertation in Nursing . Kerman University of Medical Sciences. 2012.

38. Cheavens SJ, Feldman BD,Woodward JT, Snyder,CR. Hope in cognitive psychotherapies: on working with client strengths Journal of Cognitive Psychotherapy: An International Quarterly, 2006; 20(3):135-145.

39. Sotodeh-Asl N, Neshat-Dust H, Kalantari M, Talebi H, Khosravi A. Comparison of Effectiveness of Two Methods of Hope Therapy and Drug Therapy on the Quality of Life in the Patients with Essential Hypertension. 2010; 2(1): 27-34.[persion].

40. Effectiveness of Cognitive-Behavioral Group Therapy on anxiety, depression and life expectancy in women with breast cancer, women sociology, 2010; 4.[persion].

41. Yu, DS ; Lee, DT; Woo, J. Effects of relaxation therapy on psychologic distress and symptom status in older Chinese patients with heart failure. J Psychosom Res, 2007; 62(4): 427-37.

42. Nezu , AM ; Nezu , CM ; Felgoise , SH \& et al.Problem solving therapy improved quality of life and reduced pyschological distress in adults with cancer . J Consult Clin Psychol 2004; 71: 1036-1048.

43. Shoaa kazemi ,M. Momeni, M.The effective protective intervention(Logo therapy) on recovery of Quality of life PTSD students in Bam city.1th congress of powerment \& promotion women activity. (1389) Cross red.p34.

44. Fallahzadeh H, Hadian E. the compare of life expectancy in male and female in yazd state between 1999-2005. Journal od yazd university, Shahid sadoghi, 2009; 14(4): 55-58. 